\title{
COMUNICACIÓN PARA EL CAMBIO SOCIAL EN LA EMERGENCIA DE LA ALFABETIZACIÓN DIGITAL
}

\author{
COMMUNICATION FOR SOCIAL CHANGE \\ IN THE APPEARANCE OF DIGITAL \\ ALPHABETIZATION
COMUNICAÇÃO PARA A MUDANÇA SOCIAL NA EMERGÊNCIA DA ALFABETIZAÇÃO
DIGITAL

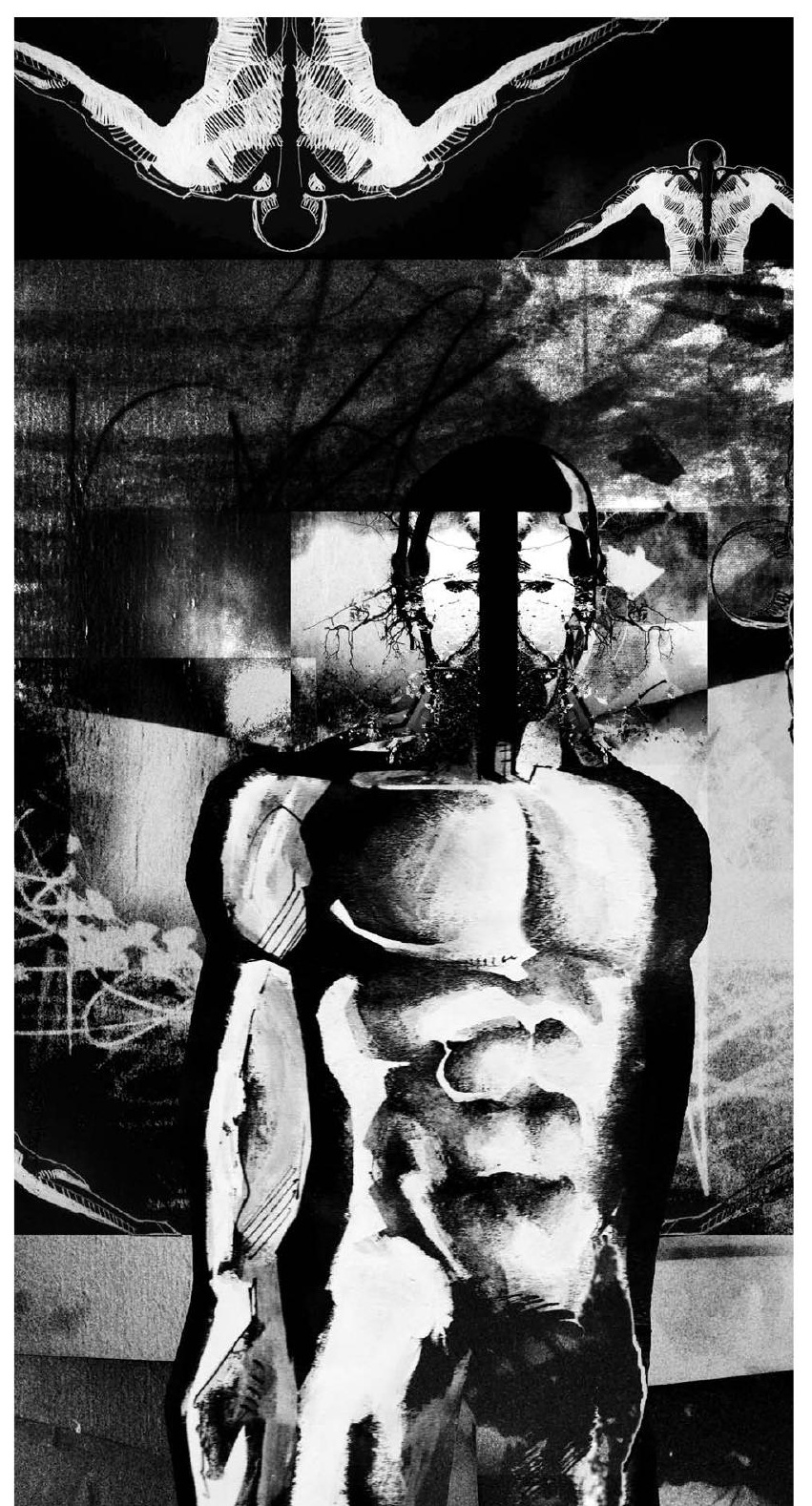

Por:

\section{Luis Fernando Gasca Bazurto ${ }^{1}$}

Profesor

Corporación Unificada Nacional de Educación Superior - CUN, Colombia

luis_gasca@cun.edu.co

Elizabeth Martínez Moreno ${ }^{2}$

Estudiante

Corporación Unificada Nacional de Educación Superior - CUN

elizabeth.martinez@cun.edu.co

Johanna Alexandra Tautiva ${ }^{3}$

Estudiante

Corporación Unificada Nacional de Educación Superior - CUN

johanna.tautiva@cun.edu.co 
Resumen: El presente artículo reflexiona sobre la práctica enseñanza aprendizaje en el contexto de la alfabetización digital dirigida a jóvenes de comunidades vulnerables desde la investigación formativa. Dicho escenario se encuentra determinado por una brecha generacional que separa a los nativos digitales de los migrantes digitales y la dificultad de acceso a la tecnología. La base metodológica se sustenta en la lectura documental. Los conceptos son: investigación formativa, dialogo de saberes, alfabetización audiovisual, transmedia y comunicación para el cambio social. Se expone que a través de la alfabetización digital las comunidades pueden mejorar sus entornos y vidas. Sin embargo, en el escenario expuesto se deben buscar alternativas dialógicas sobre la base de intereses comunes entre la academia, los estudiantes y las comunidades para superar las brechas socioeconómica, tecnológica y generacional que condiciona el escenario de la alfabetización digital.

Palabras clave: Diálogo, conocimiento, transmedia, alfabetización, audiovisual.

\begin{abstract}
This article reflects on teaching practical learning in the context of digital literacy aimed at young people from vulnerable communities from the formative research. Such a scenario is determined by a generational gap between digital natives and digital immigrants difficulty of access to technology. The methodological basis is based on the documentary reading. The concepts are: formative research, knowledge dialogue, media literacy, transmedia and communication for social change. It states that through digital literacy communities can improve their environment and lives. However, in the scenario exposed dialogic alternatives should be sought on the basis of common interests between academics, students and communities to overcome socioeconomic, technological and generational gaps that determines the scenario of digital literacy.
\end{abstract}

Keywords: Dialogue, knowledge, transmedia, literacy, audiovisual.

Resumo: Este artigo reflexiona sobre a prática de ensino-aprendizagem no contexto da alfabetização digital, dirigida aos jovens de comunidades vulneráveis desde a pesquisa formativa. Este cenário encontra-se determinado por uma barreira geracional que separa aos nativos digitais dos migrantes digitais e a dificuldade de acesso à tecnologia. A metodologia está baseada na leitura documental. Os conceitos são: pesquisa formativa, diálogo de saberes, alfabetização audiovisual, transmídia e comunicação para a mudança social. Expõe-se que, por meio da alfabetização digital, as comunidades podem melhorar seus contextos e vidas.

Porém, neste cenário, é preciso achar alternativas dialógicas a partir de interesses comuns entre a academia, os estudantes e as comunidades para superar a barreiras socioenómica, tecnológica, geracional, as quais condicionam a alfabetização digital.

Palavras-chave: Diálogo, conhecimento, transmídia, alfabetização audiovisual. 


\section{Introducción}

El medio audiovisual ha cambiado gracias a la influencia de las tecnologías de la información. Internet ha determinado una nueva generación de individuos imbuidos en la tecnología y el entretenimiento que la misma produce, denominados nativos digitales. En este ámbito, la transmedia proporciona el medio natural para que los jóvenes socialicen, disfruten y se sientan a gusto. Por otro lado, la mayoría de los profesores, migrantes digitales, tienen dificultades para lograr interactuar con sus alumnos porque existe una brecha generacional y tecnológica que se acrecienta cada vez más. Pues bien, hoy más que nunca el docente se debe preguntar: ¿Cómo enseñar? ¿para quién enseñar? ¿es útil lo que se enseña? Más aún, si a espaldas de la realidad creada por mundos virtuales y experiencias lúdicas existe otra realidad más dura con la que existe una responsabilidad. En el escenario expuesto, ¿cómo aprovechar los instrumentos que ofrecen las narrativas transmedia para la práctica enseñanza - aprendizaje dentro del aula y que repliquen en comunidades vulnerables? La academia debe ser replicadora del conocimiento y retribuir a la sociedad. De manera que la universidad a través de sus estudiantes puede contribuir a mejorar condiciones sociales al replicar los saberes adquiridos en su práctica académica. Particularmente, la alfabetización transmediática permite que las colectividades adquieran instrumentos que les permiten exponer su entorno y su situación, a la vez compararse con otros similares. Ello facilita el acceso a otras experiencias y soluciones. Para el caso particular del vídeo Gumucio-Dagron (2001) manifestó: "De este modo, la tecnología de video se utiliza como una herramienta para la producción de mensajes y como un proceso que estimula el diálogo entre comunidades, proyectos y organizaciones" (p. 297). Lo que significa que la alfabetización transmediática facilita aún más el diálogo, pues los grupos sociales adquieren más instrumentos que les permite acceder múltiples medios, plataformas y narrativas.

De esta manera, la presente propuesta pretende reflexionar sobre qué es el diálogo de saberes y la importancia del mismo en la alfabetización audiovisual. Sobre el primer punto, se destaca la influencia que ha ejercido a lo largo de su obra el pedagogo Paulo Freire, para quien "Saber enseñar no es transferir el conocimiento, sino crear las posibilidades para su propia creación o producción”. (Freire, 1997, p. 47). El segundo concepto está en relación con la importancia que ha adquirido en los últimos años la noción de transmedia en el entorno audiovisual. En este campo de la comunicación Jenkins (2009) prefiere hablar de alfabetización mediática. Las dos ideas se pondrán en relación con la práctica académica desde la investigación formativa y la manera en que desde allí se puede contribuir a impactar comunidades vulnerables, ello como práctica que contribuye a la comunicación para el cambo social. Los conceptos señalados son dinámicos, según se describe en la figura 1. Ya que, la experiencia, el contexto particular y la relación con los actores sociales son las que determinan la práctica y los métodos a seguir. Todo ello implica la mediación constante del diálogo como facilitador. 


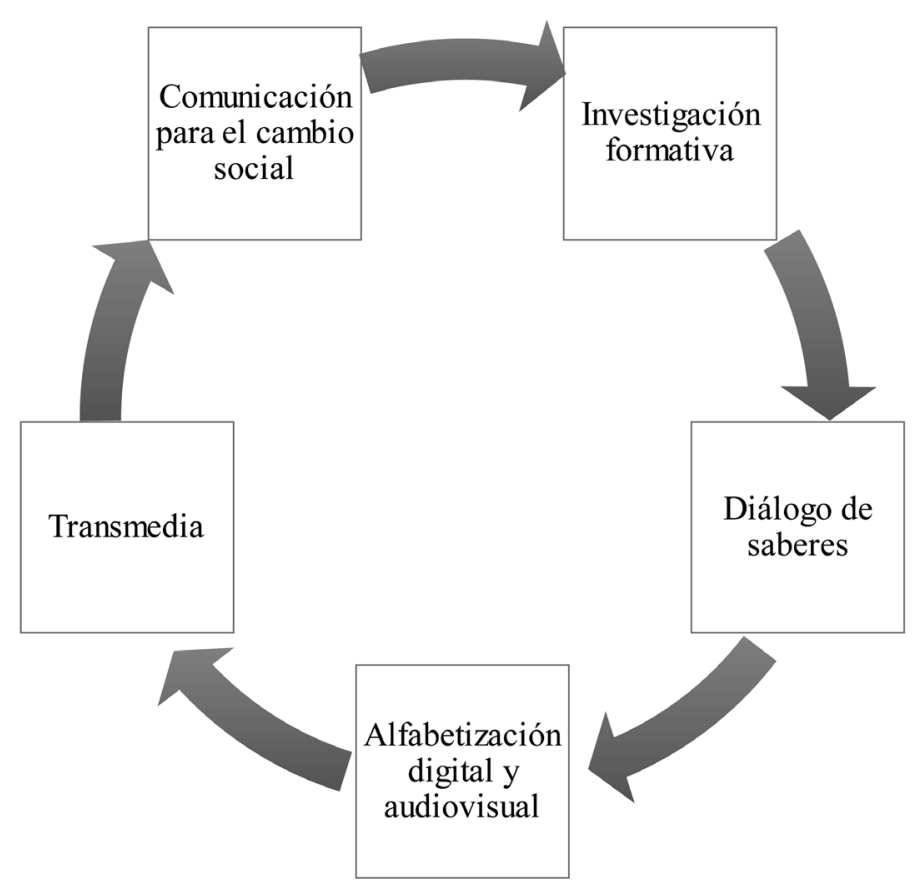

Figura 1. Los conceptos conforman un ciclo porque las experiencias son dinámicas no lineales.

\section{Marco conceptual}

El diálogo de saberes se entiende a la manera del intercambio de conocimientos y experiencias entre individuos, entendidos éstos como entes sociales que tienen conocimientos particulares ya sea a través de la práctica académica o de la experiencia empírica, la tradición, la cultura y saberes ancestrales que se han unido en la necesidad mutua y precisan construir soluciones consensuadas. Es decir:

El diálogo de saberes es un proceso comunicativo en el cual se ponen en interacción dos lógicas diferentes: la del conocimiento científico y la del saber cotidiano, con una clara intención de comprenderse mutuamente; implica el reconocimiento del otro como sujeto diferente, con conocimientos y posiciones diversas (Acevedo, Becerra, Ospina, Paucar, Córdoba, y Correa, 2009, p. 104).

Significa asumir una posición hacia el otro en el sentido de reconocerlo, de comprender que se trata de un individuo y por ello merece ser escuchado. Ello implica una noción de doble vía pues de la misma manera el otro también va a reconocer la valía de su interlocutor. En tanto los individuos quieran escuchar es posible el diálogo. Es asumir la propia valía desde los demás, en el valor del otro, en palabras de Paulo Freire (1997): "La asunción de nosotros mismos no significa la exclusión de los otros. "Es la "otredad" del "no yo" o del tú, lo que hace asumir el radicalismo de mi yo" (p. 42). El otro es 
un espejo en el que todo ser humano se ve y reconoce en una parte de sí mismo. Por consiguiente, todo ser es incompleto y solamente se puede complementar en quien tiene ante sí. El diálogo de saberes es una posición ontológica sobre la base de las relaciones humanas que se asumen de manera horizontal y democrática. Ya que desde el principio se piensa en los demás como seres responsables que construyen su destino en la correspondencia con el otro y el entorno vital.

La transmedia es un concepto que surgió de manera espontánea en respuesta al fenómeno narrativo y multimedial que imbricaba diversos medios en pro de enriquecer una historia principal. Jenkins (2009); considera que se vive en una nueva era que denomina de convergencia, pues coinciden medios e intereses, en que los consumidores van tras la caza y recolección de información de múltiples fuentes para conformar una nueva síntesis. El entorno tecnológico contemporáneo ha contribuido a que haya más facilidad de acceso a los medios, recursos y dispositivos. Asimismo, cada día hay mayor cobertura y más velocidad de conexión en red, aumentan las posibilidades que ofrece la web 2.0 y 3.0 y la nube. De manera que hoy se configuran nuevas comunidades a nivel global que facilitan el intercambio de conocimiento y la producción de toda clase contenidos por parte de entes tradicionales del sector productivo e individuos con iniciativas propias. Es decir, se esta ante un entorno de nuevas mediaciones a un nivel macro nunca antes considerado que Scolari denomina hipermediaciones. La hipermediaciones son los "procesos de intercambio, producción y consumo simbólico que se desarrollan en un entorno caracterizado por una gran cantidad de sujetos, medios y lenguajes interconectados tecnológicamente de manera reticular entre sí" (Scolari, 2012, párr. 1). Las hipermediaciones no son meramente gran cantidad de medios y sujetos sino la manera espontánea y desordenada en las que se producen las relaciones con la mediación de la tecnología digital. Ya que existe diversidad de posibilidades para acceder a un mismo tema, se pueden seguir diferentes personas que representan los diversos intereses de un mismo individuo, sean culturales, ociosos o académicos. Asimismo, es posible la participación de disímiles experiencias en red en la búsqueda de lo deseado, el intercambio de ideas con otras personas, asumir posiciones en grupo y apoyar intereses altruistas. Es decir, participar de manera diversa de diferentes temas y comunidades a nivel global y ser parte de la misma. Para complementar Baquiro (2014) percibe en las nuevas formas de comunicación la posibilidad de compartir saberes en diferentes niveles, por ejemplo, la manera en que operan las mediaciones en espacios sociales para la solución de problemas prácticos. Las hipermediaciones permiten reafirmar posturas o comprender otros puntos de vista, lo que favorece el concurso e intercambio de voces y experiencias.

La alfabetización audiovisual es una necesidad causada por la influencia de los medios en la sociedad. De acuerdo con Merayo (2000): "Sea cual sea nuestro destino, en esta revolución basada en las comunicaciones no hay ya vuelta atrás posible.Y en ella, el papel crucial va a ser desempeñado por los medios -los tradicionales: prensa, radio y televisión- y, sobre todo, por los nuevos, aquellos basados en la informática, la robótica y la telemática” (p. 35). Con la alfabetización audiovisual en pretende formar a los individuos de manera que puedan comprender la manera en que influyen los 
contenidos audiovisuales en la sociedad, asimismo tiene por objetivo capacitar a los sujetos en el manejo de los instrumentos y dispositivos audiovisuales para que puedan ser incorporarlos en sus propias prácticas comunicativas. En el mismo sentido Tyner (1996) declara:

Los alumnos pueden aprender auto-expresión creativa produciendo sus propios documentos en clase, mientras analizan los documentos ajenos. También pueden ver cómo cada medio informa de un mismo suceso de un modo diferente, debido a las limitaciones y restricciones propias del medio. La práctica de la producción y el análisis crítico son las dos partes de un programa completo de estudio de los medios (p. 7).

Jenkins (2009) manifiesta que la alfabetización audiovisual es el camino para que se le proporcionen a los estudiantes los conceptos y las competencias necesarias para que ingenien productos con significados a partir de los cuales ayuden a construir la realidad:

Media literacy is concerned with developing an informed and critical understanding of the nature of the mass media, the techniques used by them, and the impact of those techniques. It is education that aims to increase students' understanding and enjoyment of how the media work, how they produce meaning, how they are organized, and how they construct reality. Media literacy also aims to provide students with the ability to create media products (p.58).

La realidad es la construcción del mundo con conceptos, lenguajes y símbolos que determinan las relaciones sociales y la manera en que cada individuo observa e interactúa con su entorno. No obstante, la realidad es lo que existe, lo tangible, lo que el sujeto vive día a día, en su ambiento y lo impacta de manera directa en su existencia. En consecuencia, los medios pueden influir en la visión de mundo colectiva; sin embargo, la alfabetización también promueve emplear los medios de comunicación para expresar su manera de pensar y compartir información con otras sociedades. Lo anterior remite al concepto de comunicación para el cambio social. De acuerdo con Gumucio-Dagron y Tufte:

Communication for social change is a way for thinking and practice and puts people in control of the means and content of communication process. Based in dialogue of collective action, CFCS in a process of public and private dialogue through which people determine who they are that, what they need and what they want in order to improve their lives (Gumucio-Dagron y Tufte, 2006, p. XIX).

Es decir, la comunicación para el cambio social es una manera de pensar y practicar que pone a las personas en control de significados y contenidos de los procesos de comunicación. Con base en el diálogo y la acción colectiva, es un proceso de diálogo público o privado en el que las personas deciden quiénes son, qué necesitan y qué 
quieren para mejorar sus vidas. La comunicación es entendida a la manera de una interlocución de doble vía, y por ello democrática, en la que todos tienen algo que decir y de la misma manera todos están interesados en escuchar porque todos son importantes. Dicha posición pretende influir y permitir ser influenciado, enseñar y aprender. En un contexto específico, según lo exponen Botero y Obregón (2011), es la mejor manera de decidir cómo solucionar problemas sociales. Por lo tanto, la comunicación para el cambio social es muy semejante al diálogo de saberes pues necesariamente se concurre el encuentro entre para que todo individuo y desde este las comunidades mejoren su condición.

\section{Necesidad palpable}

En un mundo globalizado e hipercomunicado que ha facilitado lo que Scolari (2012) denomina las hipermediaciones, se produjo una brecha generacional que distancia a los jóvenes de los adultos en términos que antes no se había visto. Marc Prensky (2001) fue quien primero configuró el término de nativo digital y lo define de la siguiente manera:

¿Cómo deberíamos llamar a estos "nuevos" estudiantes de hoy? Algunos se refieren a ellos como la Generación-N [por Net] o Generación-D [por Digital]. Pero la designación más útil que he encontrado para ellos es Nativos Digitales. Nuestros estudiantes de hoy son todos "hablantes nativos" del lenguaje digital de los ordenadores, los videojuegos e Internet (p. 2).

La tecnología abrió una nueva brecha entre quienes nacieron y se sienten a gusto en este nuevo entorno y quienes se ven obligados a asumirlo para no quedar atrasados, es la diferencia que distingue a los nativos digitales de los migrantes digitales. Una generación altamente capacitada para emplear las facilidades de la conexión de internet y sumado a la tecnología que produce dispositivos cada vez más eficaces facilitó el fenómeno multimedia, multiplataforma y multi narrativo denominado narrativa transmedia. En los últimos años el concepto de transmedia ha sido punto de referencia en el quehacer audiovisual. Al respecto Scolari (2013) dice: "Algo ha cambiado en las últimas décadas, sobre todo desde la llegada de los procesos de digitalización y la difusión del Word Wide Web: algunos consumidores se convirtieron en prosumidores (productores - consumidores), se apropiaron de sus personajes favoritos y expandieron aún más sus mundos narrativos” (p. 27). Las circunstancias interpelan a la academia para que ésta propicie escenarios que posibiliten el diálogo, la reflexión y la experimentación para comprender dicho fenómeno y apropiarlo para buscar todas las posibilidades que le aporten a construir una mejor sociedad. Al respecto Piscitelli (2009) afirma: "En este mundo de transcodificación, transliteración, transmediación, configurador de un palimpsesto digital sin fin, tendrán lugar de ahora en más la educación y la transmisión, la socialización y la aculturación de los nativos digitales" (p. 30). Es así como se está ante una emergencia pues la tecnología y los estudiantes que la abrazan demandan de la academia de una respuesta. Amador (2012) considera 
que "se requiere la generación de prácticas pedagógicas que fomenten la exploración de diversas fuentes de información que están ubicadas en diversos formatos, lenguajes y medios (multipantalla) a los cuales se puede tener acceso por diversas vías" (Amador, 2012, p. 212). La discusión está abierta al más alto nivel. No obstante, cada región tiene sus propias necesidades.

Particularmente en América Latina, y por su puesto Colombia, la brecha que separa la sociedad se acrecienta y rezaga a diferentes comunidades que les impide vivir en un ambiente digno. La inequidad que impide el acceso a la educación, la salud, la vivienda, el estudio y trabajo ahora se suma la brecha tecnológica. El portal Internet Word Stats que recopila las estadísticas de internet a nivel mundial publicó a noviembre del 2015 el uso promedio de la red: para el caso de Norteamérica se emplea el $9.3 \%$ con una población de 357,178,284 millones respecto al 10.2 \% de Latinoamérica y el Caribe que cuenta con una población promedio de 617,049,712 millones, el 48\% de la red es usada en el Asia para un promedio de 4,032.466,882 habitantes. No obstante, el nivel de penetración por población, es decir la capacidad y cobertura de las redes para los ciudadanos es del $87.9 \%$ en Norteamérica, 55.9\% para Latinoamérica y el Caribe y $40.2 \%$ para el Asia. Lo que significa que representativamente para el conjunto de la población en las regiones mencionadas hay menos acceso en el Asia junto con Latinoamérica y el Caribe; sin embargo, en estas últimas existe la mayor demanda. En la tabla 1 se resumen las estadísticas expuestas.

\begin{tabular}{|c|c|c|c|}
\hline REGIÓN & POBLACIÓN & \% USO DE INTERNET & PENETRACIÓN \\
\hline Norteamérica & 357.178 .284 & $9.3 \%$ & $87.9 \%$ \\
\hline $\begin{array}{c}\text { Latinoamérica y el } \\
\text { Caribe }\end{array}$ & 617.049 .712 & $10.2 \%$ & $55.9 \%$ \\
\hline Asia & $4,032.466,882$ & $48 \%$ & $40.2 \%$ \\
\hline
\end{tabular}

Tabla 1. Comparación entre Norteamérica, Latinoamérica y el Caribe y Asia. Fuente: Internet Word Stats

En la región de Latinoamérica y el Caribe el tema se divide entre la oportunidad de acceso a la red y la manera en que aquellos que tienen acceso la emplean. Para el caso colombiano la Comisión de Regulación de Comunicaciones de la República de Colombia, en el documento Análisis del sector TIC en Colombia: Evolución y Desafíos (diciembre de 2010) se extraen como principales conclusiones que el diagnóstico del sector es el siguiente: "Apalancado en servicios tradicionales de voz en declive, En consolidación industrial, Con necesidades de conectividad nacional e internacional, Con oportunidades de crecimiento en la base de la pirámide a, través de la masificación del Internet, los contenidos y las aplicaciones” (p. 74). 


\section{Discusión}

Treinta años atrás el panorama mediático era objeto de discusión en los gobiernos y en la academia. En la década del 80, de acuerdo con Quevedo (2003), se planteaba el desafío que significaba la masificación de los medios de comunicación, en especial de la televisión, para el sistema educativo y se creó la necesidad de que la sociedad requería de "alfabetización audiovisual”; ésta se entendía a la manera de desarrollar elementos que permitieran a los estudiantes asumir capacidad crítica frente a lo que el público recibía. Ya que se demandaba una nueva actitud sobre el lenguaje visual para que se asumiera una posición activa frente a los mensajes, para Quevedo (2003): "Esto no implicaba el abandono de los campos tradicionales del aprendizaje, sino la aceptación de que los jóvenes viven en un mundo cultural e informativo que se ha extendido" (p. 2). En la actualidad el fenómeno es mucho más complejo pues la tecnología digital a creado un universo global altamente atravesado por diversidad de contenidos e información de una manera que en la década de los ochentas no se alcanzaba a vislumbrar. La tecnología hace posible que el hombre se pueda comunicar, acorte las distancias y acceda con más facilidad al conocimiento. Sin embargo, la velocidad con la que se produjo el tránsito de los mass media a un mundo hipermediado, al decir de Scolari (2012), produjo una separación entre quienes nacieron y se sienten a gusto en el nuevo entorno y quienes se ven obligados a asumirlo, es la distancia que separa a los nativos digitales de los migrantes digitales. Dicha brecha es una emergencia que impacta principalmente el ámbito educativo, Prenski (2001) manifiesta que "Es muy grave, porque el mayor problema que enfrenta hoy la educación es que nuestros profesores Inmigrantes Digitales, que hablan una lengua anticuada (la de antes de la era digital), están peleándose por enseñar a una población que habla un idioma completamente nuevo (p. 2). Prenski no concibe la brecha a la manera de una práctica o una actividad sino de un código, un nuevo lenguaje, que ha distanciado a los estudiantes de sus maestros y de la manera en que tradicionalmente se ha enseñado. Pisticelli (2009) manifiesta que la separación entre nativos digitales y migrantes no es simplemente tecnológica sino una manera diferente de pensar. Dice Pisticelli (2009):

Los nativos digitales, una nueva clase cognitiva, busca caracterizar la especificidad de la Generación Y, los chicos nacidos después de 1980, contemporáneos primero de la masificación en el uso de la computadora y finalmente del uso cotidiano de los celulares y el ingreso creciente en la banda ancha y la conexión a Internet (p. 30).

Las generaciones que nacieron en el momento en que se estaban llevando a cabo la revolución tecnológica digital recibió de manera natural los cambios, pues crecieron con estos y se integraron a su vida como algo cotidiano en su devenir que los condicionó a percibir, memorizar y desarrollar un lenguaje que no existía. El escenario escolar tradicionalmente ha sido un lugar de encuentro, pero a la vez un borde en la que se relacionan, hasta cierto punto, diferentes tipos de personas que pertenecen a diferentes contextos y que hacían enriquecedora la experiencia en el campus académico. No obstante, en el presente el sentimiento mutuo que tienen los 
profesores y estudiantes es que la escuela, el colegio o la universidad es un lugar en el que todos son extranjeros. Los profesores no saben acercarse de manera efectiva a sus estudiantes y estos no se sienten cómodos en el aula de clase. La razón es que sistema escolar guarda una tradición que hoy es obsoleta para los nuevos tiempos, al respecto Fanfani (2000) expresa: "Mientras que el programa escolar tiene todavía las huellas del momento fundacional (homogeneidad, sistematicidad, continuidad, coherencia, orden y secuencia únicos, etc.), las nuevas generaciones son portadoras de culturas diversas, fragmentadas, abiertas, flexibles, móviles, inestables, etc.” (p. 6). La exposición de Fanfani (2000) ya había sido anunciada por Marshall MacLuhan (1995) cuando dedujo el tipo de construcción mental que esperaba se iba a conformar en el común del ciudadano estadounidense:

Para el año 2020, los Estados Unidos adquirirán un cambio psicológico distintivo de una dependencia en el pensamiento visual, uniforme y homogéneo, de variedad del hemisferio izquierdo, a una mentalidad configurativa multifacética que hemos intentado definir como pensamiento auditivo-táctil del hemisferio derecho (p. 93).

El hecho es que la afirmación de McLuhan (1995) se adelantó más de lo esperado y no solamente para una sociedad tecnológica sino para el conjunto del globo pues, antes de que se cumpliera lo ya dicho, Quevedo (2003) expresó: Debemos reconocer, por ejemplo, que somos analfabetos audiovisuales, antes de colocarnos en el rol de pedagogos de las imágenes; y a esto agregar nuestra dificultad para ingresar al mundo digital ya que, cuando lo hacemos, nuestra velocidad de aprendizaje es menor a la de los jóvenes y niños" (p. 5). La posición compartida y complementaria de Prenski (2001), Pisticelli (2009), Fanfani (2000), McLuhan (1995) y Quevedo (2003) expresan que es un hecho la emergencia de la brecha digital y para ser superada se debe asumir como tal y repensar el sistema educativo tradicional.

Los jóvenes de hoy siguen e interactúan con diversos contenidos y formatos web, en redes sociales, blogs y diferentes sitios virtuales sin que les preocupe que exista un concepto que abarca todo lo que ellos hacen y los denomina nativos digitales. Los profesores conocen y comprenden el fenómeno de manera teórica, por conversaciones, la prensa, e incluso porque los impulsa cierta curiosidad sobre el tema, pero no saben cómo vivir la experiencia para transmitirla. La brecha manifiesta se produce por la distancia con la experiencia vivida en el mundo digital que avanza muy rápido y no deja casi espacio para pensar, el tiempo para cavilar, especular, examinar y discutir que tradicionalmente caracteriza el ámbito académico. Por otro lado, los jóvenes conforman parte de su existencia con la experiencia que descubren, viven y los forma en la red, ello de por sí implica un cambio en las relaciones humanas de una manera distinta. "Las formas tecnológicas de vida son demasiado rápidas para la reflexión. En la aceleración, la cultura es cada vez más efímera", dice Piscitelli (2009, p. 307). No obstante, no existe punto de retorno pues la revolución de las comunicaciones es irreversible, afirma Merayo (2000), y agrega: "Y en ella, el papel crucial va a ser desempeñado por los medios - los tradicionales: prensa, radio y televisión-y, sobre todo, por los nuevos, 
aquellos basados en la informática, la robótica y la telemática” (p. 35). El panorama expuesto, que a veces suena apocalíptico, debe conducir a repensar la manera en que estamos situados en el mundo tecnológico que necesariamente compartimos. Los medios de comunicación han sido parte de nuestras vidas desde tiempo atrás y han erigido una manera de pensar en gran parte fundamentada y altamente codificada en imágenes y sonidos; por ello no ha desaparecido el medio lenguaje escrito. De acuerdo con Prado (2001) la actualidad no supone olvidar unos códigos para reemplazarlos por otros; al contrario, la novedad es que los viejos códigos que han implantado los medios de comunicación se han sumado nuevos que en muchos casos los complementan. De manera que "El concepto de alfabetización, en consecuencia, necesita ampliar sus límites semánticos para dar respuesta a la necesidad educativa de instruir en estos nuevos y diversos lenguajes" (Prado, 2001, p. 163). En el mismo sentido, para Aguaded (1997): "La comunicación en medios de comunicación, cuyo objetivo básico es la alfabetización audiovisual para la formación de ciudadanos críticos y autónomos que conozcan y de manera crítica y usen creativamente los nuevos lenguajes de comprensión y expresión de la realidad" (p. 102). La esencia de la alfabetización audiovisual es en sí la misma de la alfabetización digital pues como afirma Merayo (2000): "Por otro lado, sólo desde la competencia comunicativa (saber hacer) es posible constituirse en consumidores críticos (saber juzgar) y en miembros activos y participantes de los procesos sociales de comunicación (saber estar), evitando así que sólo unos pocos tengan un efectivo acceso a los medios" (p. 38). La emergencia de la academia en su misma esencia y lo que la rezaga de las nuevas generaciones, es decir enseñar a pensar en la manera en que se producen y se transfieren las relaciones comunicativas.

La antinomia de la coyuntura digital parece impedir que se puedan aprovechar de manera deseable las posibilidades que permiten la velocidad de comunicación e interacción para hacer un mundo socialmente más incluyente. La brecha generacional entre nativos y migrantes digitales ocupa mucho la atención mientras gran parte de la población mundial no hace parte de los países desarrollados en los que la mayoría de la población tiene acceso a internet y tiene los recursos para adquirir dispositivos digitales. Más aún, muchos de los niños del primer mundo crecieron en hogares en los que sus padres podían permitirse un pc para el hogar. En el contexto expuesto es que Prenski (2001) enunció el concepto de nativos digitales. La otra parte del mundo padece serios problemas sociales de manera que para muchos grupos es más importante sobrevivir que conectarse a internet. Gumucio-Dacron, (2001) considera que la tecnología podría facilitar el desarrollo de las comunidades y constituirse en un instrumento generador de desarrollo, pero se especula mucho y existe poca experiencia. Por lo tanto, el autor manifiesta: "De alguna manera, la carrera para definir en el papel (en realidad, sobre todo en discusiones por correo electrónico o en páginas Web), lo que la Internet debería ser, es una reacción legítima al constatar que la Internet ya es algo que no corresponde a lo que querríamos que fuera” (p. 30). La afirmación de Gumucio-Dacron (2001) se sustenta en lo ya dicho, el usuario típico de los recursos digitales que brinda la red hace parte de un tejido social diferente, por ejemplo, al contexto latinoamericano. Al mismo tiempo, la gran mayoría de los usos, tendencias, contenidos, y demás, son generados por la cultura que produjo los nativos 


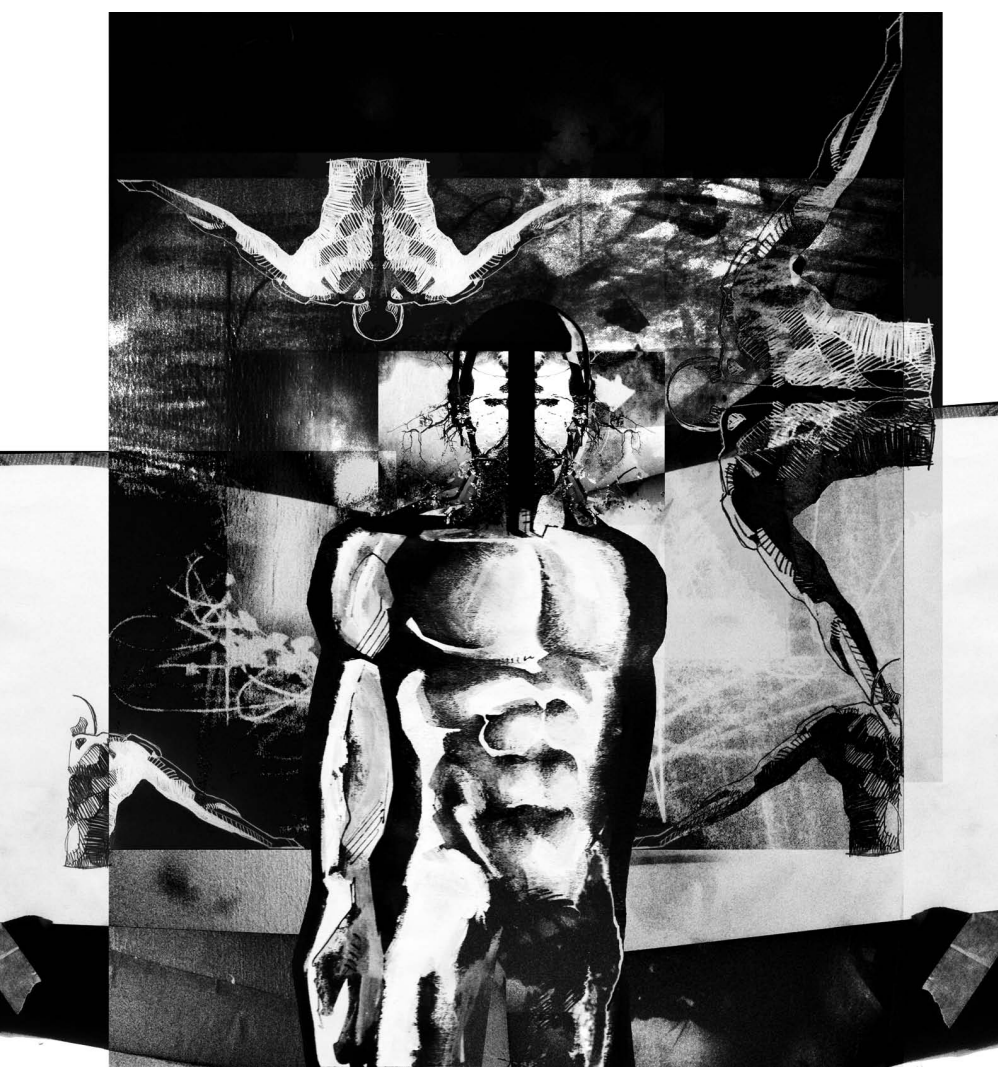

digitales. Llegado a este punto de la discusión el panorama es mucho más complejo del planteado al principio puesto que la brecha digital que condicionaba un distanciamiento generacional que replicaba en la academia se suma la brecha social y el predomino cultural del mundo desarrollado que permea al conjunto de las sociedades de manera global. La respuesta a la pregunta tácita que se ha generado - ¿qué debemos hacer? - necesariamente se orienta de nuevo hacia la academia. De acuerdo con lo que expresa Merayo (2000) la prioridad de la escuela es enseñar a comunicar. De otra manera, ¿cómo aprovechar los instrumentos que ofrecen los medios digitales para la práctica enseñanza aprendizaje y que repliquen de manera eficaz en la sociedad? Lo anterior necesariamente a conduce a un camino integral en el que deben interactúan los docentes, los estudiantes y la comunidad.

La enseñanza de los medios de comunicación en el mundo hipermediado de la red implica ayudar a las nuevas generaciones a asumir una posición reflexiva, comprensiva, crítica, participativa y dialógica. El diálogo tradicionalmente ha sido el instrumento mediador y en la emergencia digital también sigue vigente. Todo tipo de encuentro necesariamente produce tensión entre teoría y práctica ya que entran en juego diferentes percepciones académicas y vivenciales. Escuchar es la oportunidad para propiciar el intercambio y la confianza pues el diálogo es un acto de fe en el otro, como expresa Freyre (1997). Si entre los actores involucrados se abre un espacio de cordialidad y certidumbre mutua la enseñanza de los instrumentos digitales solo es un pretexto para propiciar el mutuo reconocimiento. El diálogo desde el aula trasciende a la realidad social sobre la que finalmente el estudiante ha de ejercer su influencia en calidad de profesional, como manifiesta Freire (1997): "Quien piensa acertadamente esta cansado de saber que las palabras a las que les hace falta la corporeidad del ejemplo poco o casi nada valen. Pensar acertadamente es hacer acertadamente". (Freire, 1997, p. 35). El estudiante que tiene la experiencia de retribuir a la comunidad comprende que las competencias adquiridas en el aula de clase son mucho más valiosas de lo que podría asumir solamente desde su entorno académico. De esta manera los estudiantes se pueden transformar en instrumento mediador y de réplica que permita abrir canales de comunicación, o diálogo, entre la academia y la comunidad. La brecha digital se reduce si los estudiantes suministran a la colectividad los recursos críticos y materiales para manifestarse con los instrumentos digitales. Un grupo social que comprende el alcance que implica ser escuchado se permite reconocer y compartir sus modos de vida, problemas y, por supuesto, sus saberes. 
En la educación, el diálogo de saberes es una noción en la que el docente reconoce al estudiante como un ser pensante cuya experiencia de vida le permite enriquecer su proceso de formación y comprometerlo desde la sana discusión con sus compañeros y otros docentes. Las posibilidades que ofrece la convergencia de los medios contribuye a formar un vínculo entre el aprendizaje y el entorno real a través del diálogo en el escenario de la práctica educativa. Ya que la interconexión y la comunicación entre individuos promueve necesariamente el intercambio de ideas, pensamientos y saberes, la academia debe coadyuvar a la transformación social junto con sus educandos. Rogers (1989) propone que el proceso participativo genera el cambio social y promueve avances sociales y materiales para que las comunidades tengan un mayor control de su entorno. Desde el aula la investigación formativa es el método que lo hace posible. En el sentido expuesto, Pérez y Moya (2008) conciben que todo proyecto de investigación debe tener como propósito aprender a pensar la realidad y al individuo en sí mismo, pues: "la investigación permite la relación teórica práctica, esto requiere que se asuma al docente como un orientador que, al propiciar el diálogo de saberes, facilite la puesta en práctica de los conocimientos para la transformación de los contextos comunitarios" (Pérez y Moya, 2008, p. 458). La experiencia que adquiere el estudiante al ejercer su práctica académica en comunidades vulnerables le permite observar e interactuar con ámbitos, en muchos casos, ajenos a su entorno. Tradicionalmente dicha práctica se orienta a proporcionarle a las comunidades alternativas que les permita mejorar en algún aspecto su condición de vida. En este sentido Freire (1997) expresa: ¿Por qué no aprovechar la experiencia que tienen los alumnos de vivir en áreas de la ciudad descuidadas por el poder público para discutir, por ejemplo, la contaminación de los arroyos y riachos y los bajos niveles de bienestar de la población, los basureros abiertos y los riesgos que ofrecen a la salud de la gente?" (p. 31). En el mismo sentido coinciden Pérez y Moya (2008) respecto a que la práctica académica en entornos sociales vulnerables: "El estudiante no se queda en el plano de la teoría, se relaciona con lo real y puede proponer, en el desarrollo del debate sobre los saberes, sus miradas gnoseológicas para interrelacionarlas con las miradas de los demás y construir explicaciones sobre interrogantes planteados" (p. 458). La academia puede impactar positivamente en las comunidades a través de sus estudiantes. Sin embargo, ello obliga a pensar en el papel del realizador en la coyuntura de la hipermediación digital en el contexto de la vulnerabilidad de los grupos sociales marginados. No se trata solamente de concebir estrategias comunicativas para acercarse a las comunidades pues en este contexto el concepto de comunicación para el cambio social no debe ser ajeno a la coyuntura del escenario abierto y pluralista de los medios digitales.

Integrar las posibilidades que ofrecen los medios digitales al desarrollo de las comunidades no está condicionada solamente por el acceso a los dispositivos y a la conexión digital, ya que la hipermediación crea narrativas que necesitan de la participación virtual pero también material de la presencia explícita y corporal de los individuos. Las redes sociales permiten compartir preocupaciones comunes y son empleadas por particulares y organizaciones no gubernamentales para solicitar, demandar o convocar la firma de solicitudes, marchas en distintas ciudades, entre otras, y propiciar cambios. Por ejemplo, Change.org, Avaaz The Word in action, o 
De la misma manera, para Jenkins (2009) las clases de escritura creativa o arte educan y proporcionan un proceso creativo en sí mismo; en el caso de los niños, ellos tienen la oportunidad de expresarse a través de palabras, sonidos e imágenes y cambiar la manera de pensar en particular sobre sí mismos y percibir de otra manera el trabajo de los demás, en palabras del autor:

Historically, we have valued creative writing or art clases because they help to identify and train future writers and artists, but also because the creative process is valuable on its own; every child deserves the chance to express him- or herself through words, sounds, and images, even if most will never write, perform, or draw professionally. Having these experiences, we believe, changes the way youth think about themselves and alters the way they look at work created by others (Jenkins, 2009, p. 7 - 8).

Señalaba Dewey (2011), citado por Baquiro (2014), que "la experiencia estética es un acto de libertad en el que los niños, mediante experiencias -más que sometidos a extenuantes rutinas- pueden desarrollar una serie de capacidades que les serán útiles para sus vidas" (p. 73). La creación de la narrativa transmedia con base en las piezas producidas en conjunto por los estudiantes y los niños representa un ejercicio estético, social y comunicativo que en conjunto formaba una experiencia de vida. La experiencia estética es una experiencia de libertad, al decir de Deway (2011), citado por Baquiro (2014, p. 136). La lúdica promueve el desarrollo de las capacidades cognitivas que permiten al individuo concebir la sociedad y la vida de una manera reflexiva y pensar su lugar en la comunidad y la manera en que dicha posición se traduce en el ejercicio político.

El diálogo entre los sujetos de conocimiento ocurre cuando se crea un escenario propicio entre quienes tienen intereses en común. Para ello los participantes deben propiciar el diálogo para romper los vínculos de poder. Por ello, es necesario reflexionar sobre la manera en que se debe llevar a cabo el acercamiento con la comunidad para que sea efectivo. Ya que, de acuerdo con Freire (1997), en las comunidades vulnerables los individuos, sus saberes y recursos son violentados por las circunstancias socio-económicas. Sin embargo, como se ha expuesto, dichas circunstancias pueden representar un obstáculo y también una oportunidad si se logran construir la confianza desde el primer acercamiento. El interés común es una de las mejores posibilidades, según Baquiro (2014), pues: "Se trata de saberes que son producidos gracias a la interactividad (vínculos) que ejerce mediante distintos recursos, que empiezan evidenciar un saber sobre sí mismo a través de la organización de la información alusiva a preferencias y temas de su dominio como el fútbol, el Barcelona Fútbol Club, la música rock y los juegos online” (p. 65). En el un mutuo interés se propician las condiciones para iniciar un proceso dialógico entre el conocimiento práctico y la mera percepción teórica. 


\section{Conclusiones}

El diálogo entre migrantes digitales (profesores) y nativos digitales (estudiantes) al igual que cualquier diálogo solo es posible en pro de un interés común. En este sentido vale la pena preguntarse sobre los ámbitos en los cuales se debe producir el diálogo de saberes sobre la base de la alfabetización audiovisual. Ya que en la era digital los recursos están más a la mano, pero la velocidad con la que evoluciona la tecnología deja atrás al migrante digital que precisa de un mayor esfuerzo. Por otro lado, no todos los nativos digitales tienen el mismo acceso a la tecnología. Por lo tanto, la gestión del conocimiento a partir de proyectos de investigación es un recurso que ayuda promover la aplicación en un entorno real y a la vez el dialógico o intercambio de saberes. Ello implica una forma valiosa de interrelacionar lo que se tiene con lo que no se tiene. Para que el diálogo sea posible hay que propiciar situaciones de confianza, de escucha, para posibilitar el diálogo y se produzca el encuentro sobre el muto interés. Más aún, el acercamiento debe ser sincero y espontáneo para que no sea condicionado, aunque se tenga una idea previa de lo que se quiere.

El diálogo de saberes implica también la posibilidad de orientar para ofrecer soluciones, ya que supone la voluntad de una de las partes para acceder a una realidad y la otra que se haya inmersa en esa realidad para escuchar. El fin de un diálogo no siempre es proveer soluciones a problemas concretos. El intercambio de saberes solamente proporciona miradas que permiten vislumbrar alternativas para mejorar una situación o comprender que existen más opciones de vida. Las experiencias que brindan las prácticas académicas en entornos reales vulnerables les brindan a los estudiantes la oportunidad de reconocerse a sí mismos y ser protagonistas de su formación al actuar sobre necesidades determinadas, Sin embargo, la buena voluntad de las partes interesadas no es suficiente sin que medien actores que ayuden a crear las condiciones para los encuentros y coordinen los mismos. Para terminar, esta experiencia se produjo en parte de manera espontánea, pero a la vez fue necesario sistematizarla y ejercerla en términos metodológicos. No obstante, lo expuesto no pre determina un método concreto ya que las circunstancias determinan el método que hacen posible el ejercicio. Ello va en la misma vía de lo expuesto por Botero y Obregón (2011) que para terminar expresan:

Se han hecho muchas reflexiones sobre la necesidad de analizar la comunicación en términos de diálogo para obtener mejores resultados en el cambio social. Sin embargo, no encontramos muchos análisis acerca de la naturaleza, el alcance, la metodología y los contextos de esta práctica. La falta de reflexión profunda puede llevar a los académicos a la reducción de este importante concepto (p. 201). 


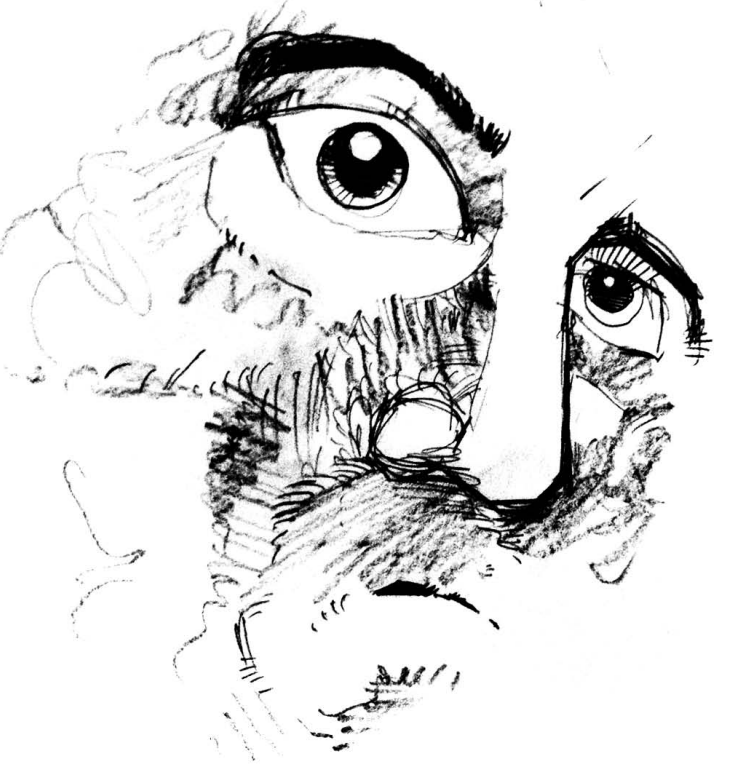

Notas

${ }^{1}$ Realizador de Cine y Televisión de la Universidad Nacional de Colombia. Candidato a Magister en Literatura y Cultura del Instituto Caro y Cuervo, Seminario Andrés Bello. Profesor del programa de Dirección y Producción de medios audiovisuales e investigador del grupo CODIM de la Escuela de comunicación y Bellas Artes de la Corporación Unificada Nacional de Educación Superior-CUN.

2 Estudiante 9 semestre de Dirección y producción de medios audiovisuales de la Corporación Unificada Nacional de Educación Superior- CUN. Integrante del semillero Germen visual.

3 Estudiante de $7^{\circ}$ semestre de Dirección y producción de medios audiovisuales de la Corporación Unificada Nacional de Educación Superior- CUN. líder del semillero "Germen Visual”.

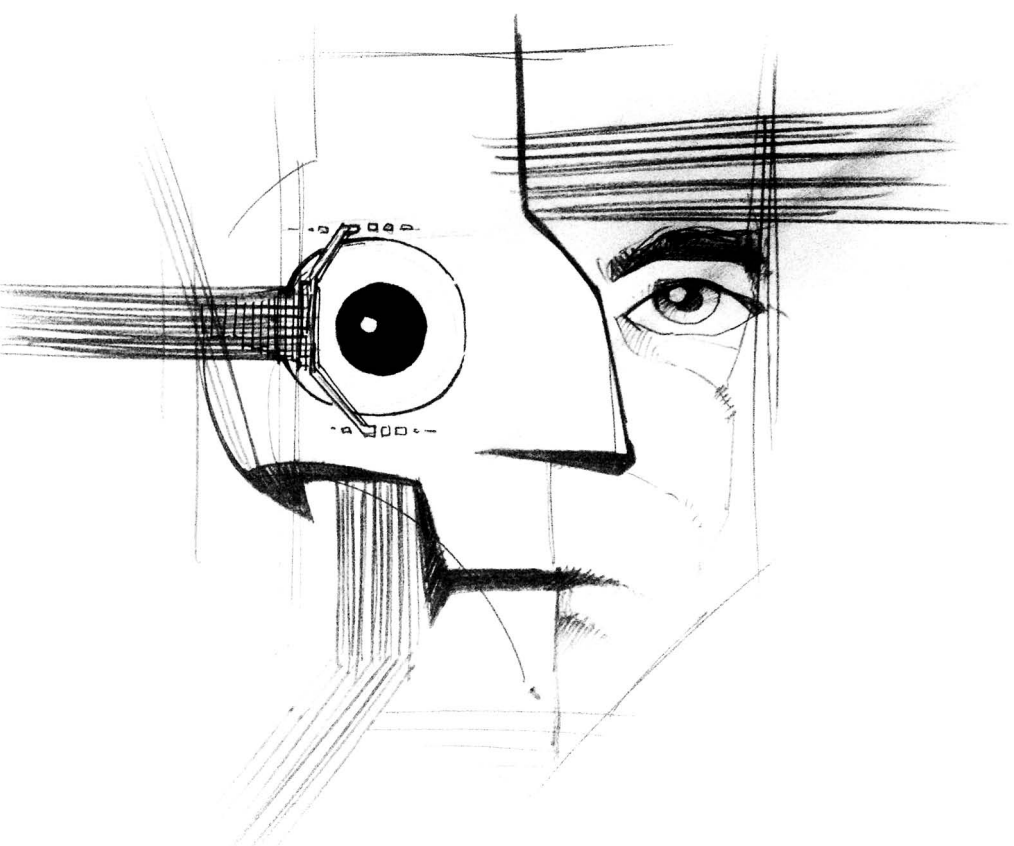




\section{Referencias}

Acevedo, M. B., Becerra, F. N., Ospina, J. N., Paucar, G. E., Córdoba, A. A., \& Correa, F. P. (2009). El diálogo de saberes como posición humana frente al otro: referente ontológico y pedagógico en la educación para la salud. Invest Educ Enferm, 27(1), 104-11. Recuperado el 2 de febrero en: http: / /www. scielo.org.co/scielo.php?pid=S0120-53072009000100011\&script=sci_pdf.

Aguaded Gómez, J. I. (1997). La televisión en el nuevo diseño curricular español. Recuperado de: http:/ / rabida.uhu.es/dspace/bitstream/handle/10272/630/b10185872.pdf?sequence=1

Amador, J. C. (2012). Transmediaciones, nativos digitales y educación. Comunica Red. Vol. 1. No 1. PP. $193-$ 216.

Ángel Botero, A., \& Obregón, R. (2011). Un análisis crítico de las perspectivas de diálogo en la literatura sobre comunicación para el desarrollo y cambio social: abordajes y desafíos. Signo y Pensamiento, 30(58), 162-177. Recuperado el 2 de diciembre de: http:/ / revistas.javeriana.edu.co/index.php/ signoypensamiento/article/download/2474/1738::pdf.

Apud, A. Participación infantil. Enrédate con Unicef. Formación del profesorado. Unicef. Recuperado el 10 de diciembre del 2014 en: http: / / www.sename.cl/wsename/otros/unicef.pdf.

Banco de desarrollo de América Latina $(2013,12)$. Hacia la transformación digital de América Latina: las infraestructuras y los servicios TIC en la región. Scioteca. Espacio de conocimiento. Recuperado 01, 2016, de http:/ / publicaciones.caf.com/media/39809/informe_tecnologiacaf.pdf

Baquiro, C. (2014). Infancias, comunicación y educación: análisis de sus mutaciones. Tesis doctoral. Universidad Distrital Francisco José de Caldas. Repositorio. Recuperado el 2 de febrero del 2015 en: http: / / repository.udistrital.edu.co/handle/11349/227.

Comisión de Regulación de Comunicaciones (2010, 11). Análisis del sector TIC en Colombia: Evolución y Desafíos - CRC. República de Colombia. Recuperado 01, 2016, de https:/ /www.google. com.co $/$ url sa $=$ t\&rct $=\mathrm{j} \& \mathrm{q}=\&$ esrc $=\mathrm{s} \&$ source $={ }_{\text {web } \& \mathrm{~cd}}=1 \& \mathrm{cad}=\mathrm{rja} \&$ uact $=8 \& \mathrm{ved}=0 \mathrm{ah}$ UKEwjIr6GB5v_MAhWMGx4KHdY_D1IQFggbMAA\&url=https\%3A\%2F\%2Fwww. crcom.gov.co\%2Frecursos_user\%2FDocumentos_CRC_2011\%2FActividades\%2520_ Regulatorias\%2FAgendaRegulatoria\%2F2011\%2FDocumentoAnalisisIndustria. pdf\&usg=AFQjCNGf8Oi-3VGUU2DLh9h--3Xf6ilLOA

Corona,Y., \& Morfín, M. (2001). Diálogo de saberes sobre participación infantil. Universidad Autónoma Metropolitana, Colectivo Mexicano de Apoyo a la Niñez, Fondo de Naciones Unidas para la Infancia (UNICEF) y Ayuda en Acción México. Recuperado el 20 de noviembre del 2014 en: http: / / www. uam.mx/cdi/dialogo/plegal.pdf.

Dagron, A. G., \& Tufte, T. (2006). Communication for social change anthology: Historical and contemporary readings. CFSC Consortium, Inc.

Fanfani, T. (2000). Culturas juveniles y cultura escolar. primera versión. IIPE Buenos Aires. Recuperado de: http:/ / files.capacitaciontic2010.webnode.es/200000004-51af452a92/EMILIO\%20TENTI\%20 FANFANI\%20CULTURAS\%20JUVENILES.pdf

Freire, P. (1997). Pedagogía de la autonomía: saberes necesarios para la práctica educativa. Siglo XXI.

Gumucio Dagron, A. (2001). Haciendo olas: historias de comunicación participativa para el cambio social. New York. Recuperado el 28 de mayo de: http:/ /www.communicationforsocialchange.org/pdf/ haciendo_olas_\%5Bf\%5D_7_23.pdf

Hernández Sampieri, R., Fernández Collado, C., \& Baptista Lucio, P. (2010). Metodología de la investigación. México: Editorial Mc Graw Hill.

IWS $(2016,01)$. Internet users in the word by regions november 2015. Internet Word Stats. Obtenido 01, 2016, de http://www.internetworldstats.com/stats.htm

Jenkins, H. (2009). Confronting the challenges of participatory culture: Media education for the 21 st century. McArthur Foundation. Recuperado el 10 de diciembre del 2014 en: http: / files.eric.ed.gov/ fulltext/ED536086.pdf. 
Jenkins, H. (2013). Transmedia 101 and Other Posts En Espangnol. Aca-Fan. The official webblog of Henry Jenkins. Recuperado de: http://henryjenkins.org/2013/11/transmedia-101-en-espangnol.html.

McLuhan, M., \& Powers, B. R. (1995). La aldea global. $3^{\text {a }}$ ed. Gedisa S.A.: Barcelona.

Merayo Pérez, A. (2000). Cómo aprender en el siglo de la información: claves para una enseñanza más comunicativa. Recuperado de: http:/ / rabida.uhu.es/dspace/bitstream/handle/10272/884/ b15199459.pdf?sequence $=1$

Obregón, R. (2009). Comunicación, desarrollo y cambio social. Portal de la Comunicación/Institut de la Comunicació UAB. Recuperado el 11 de febrero del 2015 en: http://www.portalcomunicacio. cat/uploads/pdf/49_esp.pdf.

Pérez Luna, E., \& Alfonzo Moya, N. (2008). Diálogo de saberes y proyectos de investigación en la escuela. Educere, 12(42), 455-460. Recuperado el 10 de enero del 2015 en: http: / / www.saber. ula.ve/bitstream/123456789/26300/1/articulo4.pdf.

Piscitelli, A. (2009). Nativos digitales: Dieta cognitiva, inteligencia colectiva y arquitecturas de la participación. Buenos Aires: Santillana. Recuperado de: http://mtcomunicacion.udistrital.edu.co:8080/c/ document_library/get_file?uuid=4ab09bb4-e6dc-47a9-95cd-88a8f62a4a98\&groupId=47932 .

Prado Aragonés, J. (2001). Hacia un nuevo concepto de alfabetización: el lenguaje de los medios. Recuperado de: http: / /rabida.uhu.es/dspace/bitstream/handle/10272/957/b1521767x. pdf?sequence $=1$

Prensky, M. (2001). Nativos digitales, inmigrantes digitales. On the horizon, 9(5). Recuperado de: http: / / files.educunab. webnode.cl/200000062-5aba35bb22/Nativos-digitales-parte1.pdf

Quevedo, L. A. (2003). La escuela frente a los jóvenes, los medios de comunicación y los consumos culturales en el siglo XXI. Recuperado de: http://www.cea-arg.org.ar/docu/docs/TexQueEscyMed.pdf

Rogers, E. M. (2010). Diffusion of innovations. Simon and Schuster. Recuperado el 2 de enero del 2014 en: https: / / teddykw2.files.wordpress.com/2012/07/everett-m-rogers-diffusion-ofinnovations.pdf.

Scolari, C. A. (2012). Carlos Alberto Scolari. ¿Cómo definiría el término hipermediaciones? Blog. Recuperado de: http: / / drcarlossc.blogspot.com/2012/05/como-definiria-el-termino.html.

Scolari, C. A. (2013). Narrativas Transmedia: Cuando todos los medios cuentan. Barcelona: Grupo Editorial Planeta.

Tyner, K. (2016, 01). Conceptos clave de la alfabetización audiovisual. UNED. Recuperado 01, 2016, de http://www2.uned.es/ntedu/espanol/matricula-abierta/lectura-de-la-imagen/ zonacomun/N_ColaborTyner.htm

Recibido: febrero 2016/ Aprobado: abril 2016 